\title{
Prevalence, Causes, and Risk Factors for Functional Low Vision in Nigeria: Results from the National Survey of Blindness and Visual Impairment
}

\author{
Gabriel Entekume, ${ }^{1}$ Jaymini Patel, ${ }^{2}$ Selvaraj Sivasubramaniam, ${ }^{3}$ Clare E. Gilbert, ${ }^{3}$ \\ Christian C. Ezelum, ${ }^{4}$ Gudlavalleti V. S. Murtby, ${ }^{3}$ M. Mansur Rabiu, ${ }^{5}$ for the \\ Nigeria National Blindness and Visual Impairment Study Group ${ }^{6}$
}

Purpose. To estimate prevalence and describe causes of functional low vision (FLV) among a nationally representative sample of Nigerian adults, assess socioeconomic risk factors, and estimate the number of adults in Nigeria who might benefit from low vision assessment or rehabilitation services.

Methods. Multistage, stratified, cluster random sampling with probability proportional to size procedures were used to identify a nationally representative sample of 15,027 persons aged 40 years or older. Distance vision was measured using a reduced $\log$ MAR tumbling E-chart. All participants with presenting acuity of $<6 / 12$ in one or both eyes had their corrected acuity measured and underwent detailed clinical examination to determine the cause. FLV was defined as best corrected vision $<6 / 18$ in the better eye, after excluding those with no light perception in both eyes and those with treatable causes. Analysis took account of the clustered design.

REsults. In all, 13,591 individuals were examined in 305 clusters (response rate, $89.9 \%$ ). The crude prevalence of FLV was $3.5 \%$ (95\% confidence interval, 3.1-3.9\%). This was lower than the prevalence of blindness, which was $4.2 \%$. Glaucoma was the most common cause and age the most important risk factor. There are estimated to be approximately 5000 adults with FLV per million population and 340 who are totally blind. Only $9.3 \%$ of those with FLV were of working age and literate.

Conclusions. These are the first data on the prevalence, causes, and risk factors for FLV from Africa. Results support studies from Asia that the prevalence of FLV is lower than previously

From the ${ }^{1}$ Vision Health Services, Ikeja, Lagos State, Nigeria; the ${ }^{2}$ Medical Statistics Unit and the ${ }^{3}$ International Centre for Eye Health, London School of Hygiene and Tropical Medicine, London, United Kingdom; the ${ }^{4}$ Ministry of Health, Awka, Anambra State, Nigeria; and the ${ }^{5}$ National Eye Centre, Kaduna, Nigeria.

${ }^{6}$ Additional members of the Nigeria National Blindness and Visual Impairment Study Group are listed in the Appendix.

Supported by Sightsavers International, Velux Stiftung, and Christoffel Blind Mission. Personnel were funded by their respective institutions (LSHTM; Federal and State Governments in Nigeria) and field allowances for the staff were borne by the International NGOs who funded the study. Costs for publication of the manuscript are being borne by the International Centre for Eye Health out of the grants provided for the study.

Submitted for publication January 27, 2011; revised May 27 and July 1, 2011; accepted July 2, 2011.

Disclosure: G. Entekume, None; J. Patel, None; S. Sivasubramaniam, None; C.E. Gilbert, None; C.C. Ezelum, None; G.V.S. Murthy, None; M.M. Rabiu, None

Corresponding author: Gudlavalleti V. S. Murthy, International Centre for Eye Health, London School of Hygiene and Tropical Medicine, Keppel Street, London WC1E 7HT, United Kingdom; gvs.murthy@1shtm.ac.uk. thought. Because the majority of adults with FLV in Nigeria live in rural areas and are elderly and not literate, further research is required to assess the nature of the interventions required and who might best deliver them. (Invest Ophthalmol Vis Sci. 2011;52:6714-6719) DOI:10.1167/iovs.11-7293

Thdividuals with visual loss from conditions that cannot be 1 treated to restore visual function can often benefit from low vision services that allow them to live more independent lives. ${ }^{1-3}$ In 1993, the World Health Organization (WHO) defined people with low vision for use in population-based surveys to estimate the prevalence of visual loss from untreatable causes of low vision as "a person who has impairment of visual functioning even after treatment and/or standard refractive correction, and has a visual acuity (VA) of $<6 / 18$ to perception of light (PL) in the better eye, or a visual field of $<10^{\circ}$ from the point of fixation, but who uses, or is potentially able to use vision for the planning and/or execution of a task." ${ }^{4}$ To distinguish this definition from the WHO International Classification of Diseases (ICD-10) definition, the term "functional low vision" (FLV) has been used. ${ }^{5,6}$ The definition of FLV is not intended to be restrictive because, in reality, individuals who fall outside this definition may also benefit from low vision services, such as those with a corrected VA of at least $6 / 18$ in one or both eyes but who have, for example, paracentral scotomas, reduced contrast sensitivity, or pronounced photophobia. ${ }^{7}$ In addition, individuals who have other comorbidities that may prevent sight-restoring treatment (i.e., cataract surgery) or who are dependent on other family members may also benefit from low vision services, in that these have been shown to be independent predictors of rehabilitation needs. ${ }^{8}$ Thus, data from prevalence surveys will constitute a minimum estimate of the number of people who need assessment for low vision services.

Despite the provision of low vision services being a priority of VISION 2020, the global initiative of the WHO and the International Agency for the Prevention of Blindness, ${ }^{9}$ there are very limited data on the epidemiology of FLV. To our knowledge there are only three publications of populationbased prevalence data that have used the definition outlined earlier; one study analyzed data from eight standardized surveys of refractive errors in children, ${ }^{6}$ whereas the other two are surveys of adults, one in India ${ }^{10}$ and the other in Pakistan. ${ }^{5}$ Both studies of adults showed that the prevalence of FLV was lower than previously anticipated, being lower than the prevalence of blindness (i.e., presenting visual acuity of $<3 / 60$ in the better eye from all causes), which has important implications for those planning and providing low vision services. ${ }^{11}$

The purpose of this article was to report data on the prevalence and causes of FLV in Nigerian adults, to identify socioeconomic risk factors, and to estimate national needs for low 
vision services as well as rehabilitation for those with no light perception in both eyes. The data were collected during the Nigerian national survey of the prevalence and causes of visual impairment and blindness, fieldwork for which was undertaken between 2005 and $2007 .^{12}$

\section{Methods}

Details of the survey methodology and the main findings have already been published. ${ }^{12-15}$

\section{Survey Procedures}

Ethical approval for the study was provided by the London School of Hygiene and Tropical Medicine and the Federal Government of Nigeria. The study adhered to the tenets of the Declaration of Helsinki and written informed consent was obtained from participants after explaining the study.

The country is divided into 6 administrative geopolitical zones (GPZ), 36 States, and the Federal Capital Territory of Abuja. Each State is subdivided into local government authorities, which are the smallest administrative unit.

\section{Study Population and Sample Size}

The sample size for the main survey was calculated using an estimated blindness prevalence of $5 \%$, with an absolute precision of $0.5 \%$ at $95 \%$ confidence, assuming a design effect of 1.75 and a response rate of $85 \%$. The calculated sample size was 15,027 persons aged 40 years or older. Assuming the prevalence of FLV to be slightly lower than the prevalence of blindness, this sample size was large enough to give a precise estimate of the prevalence of FLV (i.e., 3.5\% with an absolute precision of $0.5 \%$ at $95 \%$ confidence).

\section{Sampling Process}

Multistage, stratified (by administrative geopolitical zone and urban/ rural location), cluster random sampling with probability proportional to size procedures were used to identify a nationally representative sample. In each cluster the center of the cluster was located and a random start was made by spinning a bottle. The enumeration team started to identify eligible adults by going house to house, following an established protocol. Enumeration continued until 50 adults aged 40 years or older, who were normally resident (defined as continuously resident for at least the past 3 months), were identified. In small villages, if there were fewer than 50 eligible adults, the nearest village was included. Among the 310 clusters identified, 226 were in rural areas and 84 in urban areas.

After obtaining written informed consent, personal and demographic data were collected at the time of enumeration and participants were invited to attend the examination site set up in each cluster. Those who did not attend for examination were traced and offered examination at home. If after three visits they were not examined they were deemed nonrespondents and were not replaced.

\section{Clinical Examination}

Personal, demographic, and anthropometric data were collected at the examination site by an interviewer and trained field staff. All participants had their presenting and uncorrected distance VA measured in each eye separately by a trained ophthalmic nurse using a reduced logMAR tumbling E-chart, which has three "tumbling " E optotype letters per line and a border surround ${ }^{16}$ comprising bars of the same stroke width, as used in other VA testing charts. These charts have been used in other national surveys of visual impairment (Bangladesh and Pakistan surveys). ${ }^{17,18}$ VA was measured in a shaded area outdoors and individuals who could not read at least two letters on the top line of the chart at 4 meters were retested at 1 meter. Those who could not read any letters at 1 meter were tested for counting fingers, hand movements, and perception of light by an ophthalmologist. All with a presenting acuity of $<6 / 12$ in one or both eyes had their VA retested by "subjective" refraction with the autorefraction results placed in a trial lens frame.

All participants had a basic eye examination by an ophthalmologist, followed by automated refraction (Takagi ARKM-100; Takagi Seiko, Takaoka, Japan) and A-scan biometry performed by a trained optometrist. The following participants underwent a detailed eye examination by a second ophthalmologist: those with (1) presenting VA $<6 / 12$ in one or both eyes, (2) history of cataract surgery or couching, (3) any abnormality of the disc or retina detected during the basic eye examination, and (4) every one in seven participants regardless of any other findings. The latter were to provide data on ocular parameters for a normative data set. Causes of visual loss were assigned to each eye for all individuals with a VA of $<6 / 12$ in one or both eyes and one cause was determined for the individual, using WHO-recommended algorithms. ${ }^{19}$

Simple treatments and spectacles were provided to those needing them free of charge at the study site and those requiring further investigations or surgery were referred to the nearest eye hospital. Nonparticipant members of the community who had ocular complaints were also examined by an ophthalmic nurse.

Two teams undertook the field work, visiting different clusters simultaneously. Each team comprised two ophthalmologists, one optometrist, two ophthalmic nurses, and four enumerators. The core team, comprising the two optometrists and four ophthalmologists, remained essentially unchanged throughout the field work. In each GPZ new enumerators and ophthalmic nurses were recruited so that at least some team members were familiar with local languages, traditions, and events (for the events calendar used to confirm age). Before field work in each of the six GPZs there was a 2-week period of intensive training and interobserver assessments. The field teams were supported by a Project Manager and Liaison Officer.

\section{Statistical Analysis}

The definition used in this study was as suggested by the WHO. ${ }^{20}$ First, all individuals whose best corrected VA was $<6 / 18$ in both eyes were identified. Those with no light perception in both eyes were excluded, as were those with treatable causes of visual loss (i.e., those with cataract, posterior capsule opacification, and refractive errors). Four cases in which underlying disorders or causes could not be determined were also excluded. All other causes were deemed untreatable, including corneal scarring, because services for corneal grafting are not available in Nigeria.

The data were entered in custom-made database software (Access 2010; Microsoft Corp., Redmond, WA), cleaned, and analyzed using a statistical package (Stata 11; StataCorp, College Station, TX). Data are presented on the prevalence of FLV for different sociodemographic characteristics stratified by sex. The causes of FLV are described in relation to specific sociodemographic characteristics. Design-based $F$-statistics were calculated to establish associations between the prevalence of FLV and sociodemographic factors.

Univariate and age-sex-adjusted logistic regression modeling were used to explore associations with demographic factors. Variables that were significant at the 0.2 level in the univariate analyses were included in the multivariable model. Pairwise interactions were assessed simultaneously using a Wald $F$ test. Multiple regression estimates of the independent effects of model variables were considered reliable only when interactions between these variables were not significant. Missing values were assumed to be distributed the same as available data and, thus, were excluded in all analyses.

The design effect due to stratified cluster sampling was taken into account in both the univariate and multivariate analyses to calculate confidence intervals (CIs) for prevalence estimates and odds ratios (ORs) in the regression modeling. We used "svy" commands (Stata 11), which use linearized variance estimators based on first-order Taylor series linear approximation, to compute the SEs accounting for the clustering effect arising from sampling design. 
The number of people with FLV and who were totally blind (i.e., no light perception in both eyes) in Nigeria were estimated using age-sex standardized prevalence data. We calculated directly standardized prevalence rates of FLV using the "dstdize" program (Stata 11). We used the US Census Bureau 2010 mid-year population projection for Nigeria $^{21}$ as the standard population.

\section{Results}

A total of 13,591 participants aged 40 years or older were examined (89.9\% response rate) in 305 clusters spread across the six geopolitical zones. Individuals in five clusters were not examined on account of civil unrest or lack of consent by community leaders. Those enumerated but not examined were slightly younger than those examined and were more likely to be male, although differences were not significant

The mean age of participants was 55.9 years (SD 12.4) and the median was 54 years (interquartile range, 45-65), with the greatest number being aged 40 to 49 years (Table 1). Males were marginally older than females (mean age, 56.8 and 55.2 years, respectively). The sample consisted of more females $(7345,54.0 \%)$ than males and a higher proportion of those examined lived in rural areas compared with urban areas $(78 \%$ vs. $22 \%$, respectively), reflecting the distribution of the population.

In total, 1293 participants $(9.5 \%)$ had a best-corrected VA in the better eye of $<6 / 18$. The following individuals were not included in the analysis because they did not fulfill the definition for FLV: 38 participants $(0.3 \%)$ had no perception of light in both eyes and a further 781 participants had a treatable cause in one or both eyes, mainly refractive errors $(n=141$, $1.0 \%)$ or cataract $(n=632,4.6 \%)$. Thus, the number of people with FLV was 474 (crude prevalence, 3.5\%; 95\% CI, 3.1-3.9\%; Table 1). Seventy-four participants with FLV had perception of light only in one eye and 227 were classified as blind, using the WHO definition of VA of $<3 / 60$ in the better eye. Overall, 186 individuals (39.2\%) with FLV could not correctly identify one letter on the $\log$ MAR chart at 1 meter, indicating that they would be unlikely to benefit from optical devices.
The crude prevalence of FLV was slightly higher in males than that in females (3.7\% vs. $3.3 \%$; Table 1$)$. The average age of males with FLV was very similar to that of females (67.3 years vs. 67.0 years, respectively). The South East zone had the highest prevalence of FLV (4.2\%) and the South West, the lowest (2.7\%). The prevalence of FLV increased with age in males and in females, and only a quarter were literate. Only 44 participants with FLV were of working age (i.e., younger than 60 years) and literate (i.e., only $9.3 \%$ of the total with FLV).

\section{Causes of FLV}

Glaucoma was the most common cause of FLV in both rural and urban areas, accounting for over a quarter of all cases (26.5\%; Table 2). Corneal opacity (21.5\%) was the second most common cause, some of which was attributed to acquired conditions of childhood. Corneal opacity accounted for a higher proportion of FLV in rural areas (23.5\%) compared with urban areas (13.7\%). Age-related macular degeneration was responsible for $11 \%$ of FLV. Complications of surgery, mainly cataract surgery and couching, were responsible for $4.8 \%$ of FLV. Onchocerciasis was not a common cause of FLV in Nigeria. Glaucoma was the main cause in most geopolitical regions in the country, whereas corneal opacity was found mostly in the north of Nigeria.

\section{Risk Factors for Functional Low Vision}

In univariate analysis, increasing age was strongly associated with increasing odds of FLV (Table 3). Compared with those aged 40 to 49 years, the odds of FLV increased significantly with every 10-year increase in age. The OR for the age group 50 to 59 years was 1.6 (95\% CI, 1.1-2.3) and 15.0 (95\% CI, $10.0-22.5)$ for those aged 80 years or older. Males had higher odds of FLV than that of females but this was not statistically significant. Literacy was also associated with FLV $(P=0.001)$ as was being unmarried $(P=0.001)$. Variation by GPZ was also observed, with the South East zone having the highest odds compared with the South West zone, which had the lowest

TABLE 1. Prevalence of Functional Low Vision by Age and Sex

\begin{tabular}{|c|c|c|c|c|c|c|c|c|c|c|}
\hline \multirow[b]{2}{*}{ Parameter } & \multicolumn{3}{|c|}{ Female } & \multicolumn{3}{|c|}{ Male } & \multicolumn{3}{|c|}{ Total } & \multirow[b]{2}{*}{$\boldsymbol{P}$} \\
\hline & $\boldsymbol{n}$ & FLV & Prev & $\boldsymbol{n}$ & FLV & Prev & $\boldsymbol{n}$ & FLV & Prev & \\
\hline Age group, y & & & & & & & & & & $0.001^{*}$ \\
\hline $40-49$ & 2,805 & 22 & 0.8 & 2,084 & 28 & 1.3 & 4,889 & 50 & 1.0 & \\
\hline $50-59$ & 1,928 & 29 & 1.5 & 1,649 & 28 & 1.7 & 3,577 & 57 & 1.6 & \\
\hline $60-69$ & 1,467 & 86 & 5.9 & 1,306 & 60 & 4.6 & 2,773 & 146 & 5.3 & \\
\hline $70-09$ & 815 & 60 & 7.4 & 838 & 67 & 8.0 & 1,653 & 127 & 7.7 & \\
\hline $80+$ & 330 & 46 & 13.9 & 369 & 48 & 13.0 & 699 & 94 & 13.4 & \\
\hline Geopolitical zone & & & & & & & & & & 0.3984 \\
\hline South West & 1,581 & 36 & 2.3 & 1,147 & 38 & 3.3 & 2,728 & 74 & 2.7 & \\
\hline North Central & 1,140 & 37 & 3.2 & 889 & 39 & 4.4 & 2,029 & 76 & 3.7 & \\
\hline North East & 838 & 33 & 3.9 & 889 & 30 & 3.4 & 1,727 & 63 & 3.6 & \\
\hline North West & 1,748 & 67 & 3.8 & 1,845 & 57 & 3.1 & 3,593 & 124 & 3.5 & \\
\hline South East & 992 & 34 & 3.4 & 670 & 36 & 5.4 & 1,662 & 70 & 4.2 & \\
\hline Residence & & & & & & & & & & 0.2564 \\
\hline Rural & 5,662 & 192 & 3.4 & 4,878 & 187 & 3.8 & 10,540 & 379 & 3.6 & \\
\hline Urban & 1,683 & 51 & 3.0 & 1,368 & 44 & 3.2 & 3,051 & 95 & 3.1 & \\
\hline Literacy & & & & & & & & & & 0.001 \\
\hline Literate & 1,993 & 26 & 1.3 & 3,932 & 91 & 2.3 & 5,925 & 117 & 2.0 & \\
\hline Illiterate & 5,352 & 217 & 4.1 & 2,314 & 140 & 6.1 & 7,666 & 357 & 4.7 & \\
\hline Marital status & & & & & & & & & & 0.001 \\
\hline Currently married & 4,815 & 89 & 1.8 & 5,942 & 203 & 3.4 & 10,757 & 292 & 2.7 & \\
\hline Currently unmarried & 2,530 & 154 & 6.1 & 304 & 28 & 9.2 & 2,834 & 182 & 6.4 & \\
\hline Total & 7,345 & 243 & 3.3 & 6,246 & 231 & 3.7 & 13,591 & 474 & 3.5 & \\
\hline
\end{tabular}

* Test for trend with decadal increase in age. 
TABLE 2. Principal Cause and Underlying Etiology of Functional Low Vision by Place of Residence

\begin{tabular}{|c|c|c|c|c|c|c|}
\hline \multirow[b]{2}{*}{ Parameter } & \multicolumn{2}{|c|}{ Rural } & \multicolumn{2}{|c|}{ Urban } & \multicolumn{2}{|c|}{ Total } \\
\hline & $n$ & $\%$ & $n$ & $\%$ & $n$ & $\%$ \\
\hline \multicolumn{7}{|l|}{ Principal cause } \\
\hline Glaucoma & 96 & 25.3 & 30 & 31.6 & 126 & 26.6 \\
\hline Corneal opacity & 89 & 23.5 & 13 & 13.7 & 102 & 21.5 \\
\hline Macular degeneration & 44 & 11.6 & 8 & 8.4 & 52 & 11.0 \\
\hline Other posterior segment & 34 & 9.0 & 13 & 13.7 & 47 & 9.9 \\
\hline Optic atrophy & 28 & 7.4 & 8 & 8.4 & 36 & 7.6 \\
\hline Chorioretinitis & 17 & 4.5 & 4 & 4.2 & 21 & 4.4 \\
\hline Phthisical & 17 & 4.5 & 1 & 1.1 & 18 & 3.8 \\
\hline Pterygium & 10 & 2.6 & 3 & 3.2 & 13 & 2.7 \\
\hline Unexplained & 35 & 9.2 & 10 & 10.5 & 45 & 9.5 \\
\hline Other & 9 & 2.4 & 5 & 5.3 & 14 & 2.9 \\
\hline \multicolumn{7}{|l|}{ Underlying etiology } \\
\hline Age-related & 177 & 46.7 & 47 & 49.5 & 224 & 47.3 \\
\hline Unknown & 89 & 23.5 & 25 & 26.3 & 114 & 24.1 \\
\hline Trachoma & 32 & 8.4 & 1 & 1.1 & 33 & 7.0 \\
\hline Measles/Vit. A def./HTEM & 29 & 7.7 & 2 & 2.1 & 31 & 6.5 \\
\hline Surgical procedure & 16 & 4.2 & 7 & 7.4 & 23 & 4.8 \\
\hline Other infections & 10 & 2.6 & 3 & 3.2 & 13 & 2.7 \\
\hline Onchocerciasis & 6 & 1.6 & 2 & 2.1 & 8 & 1.7 \\
\hline Trauma & 5 & 1.3 & 3 & 3.2 & 8 & 1.7 \\
\hline Other & 15 & 3.9 & 5 & 5.3 & 20 & 4.2 \\
\hline Total & 379 & 100.0 & 95 & 100.0 & 474 & 100.0 \\
\hline
\end{tabular}

Vit. A def., vitamin A deficiency; HTEM, harmful traditional eye medications.

prevalence (OR, 1.6; 95\% CI, 1.2-2.1). The age-adjusted analyses indicated that there was considerable confounding by age.

Logistic regression modeling was used to investigate the association of age, GPZ, sex, residence, literacy, and marital status with FLV. Residence was not associated with FLV either independently or in interaction with other model variables (Wald test, $P=0.1946$ ) and so it was dropped from the final model. Significant pairwise interactions between model variables (Wald test, $P=0.0266$ ) necessitated the fitting of two separate models: one for those who were literate and a separate one for those who were not literate. FLV was associated with older age in both models $(P=0.001)$ (Table 4$)$. GPZ differences were not significant in either model. Male sex category was associated with FLV with marginal significance in both models. The observed higher prevalence of FLV among unmarried/single/widowed (adjusted OR, 2.4) was statistically significant $(P=0.001)$ but only in the model for literate participants.

\section{Estimation of Number of People with FLV and Total Blindness}

Using the age-sex standardized prevalence of FLV of $2.7 \%(95 \%$ CI, 2.4-3.1\%) and population estimates for 2010, the number of adults aged 40 years and older in Nigeria with FLV is approximately 755,000 , or almost $5000 /$ million population (Table 5). The prevalence of total blindness adults (i.e., those with no light perception in both eyes) was $0.2 \%(95 \% \mathrm{CI}$, 0.1-0.3\%), giving an estimated total of over 50,000 people across Nigeria, or $340 /$ million population.

\section{Discussion}

In the Nigeria national survey, the crude prevalence of blindness was $4.2 \%(95 \% \mathrm{CI}, 3.8-4.6 \%),{ }^{13}$ and in the present study the crude prevalence of FLV was $3.5 \%$ (95\% CI, 3.1-3.9\%). As in the publications from India ${ }^{10}$ and Pakistan, ${ }^{5}$ the prevalence of FLV was lower than the prevalence of blindness. In this study the ratio of FLV:blindness was 1.0:1.2, whereas in Pakistan it was $1.0: 1.6 .^{5}$ In the present study only $9.3 \%$ of individuals with FLV were literate and of working age, which is similar to the findings in Pakistan (5\%). ${ }^{5}$ In Nigeria we estimate that there are approximately 5000 adults/million population (all ages) who require assessment for low vision services and a further 340 who are totally blind and who may benefit from rehabilitation services. However, this is minimum estimate because it does not include those with other comorbidities who may also benefit from low vision services, nor does it take account of those too unfit to undergo cataract surgery or who have poor visual outcomes after cataract surgery.

This study of FLV, the first population-based study in an African setting, supports data from the Asian surveys in India ${ }^{10}$ and Pakistan, ${ }^{5}$ which also reported the prevalence of FLV to be less than that of blindness. This finding, together with the realization that the vast majority of those affected lived in rural areas, were elderly, and not literate, has enormous implications for service planning. Further research is required to assess the needs of these individuals and the findings of a randomized controlled trial in India, which is comparing the location and range of interventions being provided, will provide invaluable insights. $^{7}$

In our study, glaucoma was the most common cause of FLV, whereas in the Pakistan survey glaucoma ranked third after corneal conditions and retinal diseases. In our study those who were illiterate and unmarried/single/widowed had a significantly greater risk of FLV than those who were literate or married. Lack of education and living alone or in a less supportive environment are likely to influence health-seeking behavior, leading to late detection and inadequate treatment of glaucoma. This finding also has implications for low vision services, in that glaucoma is associated with progressive loss of visual function if inadequately controlled, whereas visual loss from corneal disease is likely to remain stable. As anticipated, in Nigeria there was considerable variation in the causes of FLV by place of residence, with individuals living in rural areas

TABLE 3. Risk Factors for Functional Low Vision (Univariate Analysis)

\begin{tabular}{|c|c|c|c|c|}
\hline \multirow[b]{2}{*}{ Parameter } & \multicolumn{2}{|c|}{ Unadjusted } & \multicolumn{2}{|c|}{ Age Adjusted } \\
\hline & OR & $95 \%$ CI & OR & $95 \% \mathrm{CI}$ \\
\hline \multicolumn{5}{|l|}{ Age group, y } \\
\hline $40-49$ & 1.00 & & & \\
\hline $50-59$ & 1.6 & $1.1-2.3$ & & \\
\hline $60-69$ & 5.4 & $3.8-7.6$ & & \\
\hline $70-09$ & 8.0 & 5.5-11.9 & & \\
\hline $80+$ & 15.0 & $10.0-22.5$ & & \\
\hline \multicolumn{5}{|l|}{ Sex } \\
\hline Female & 1.00 & & & \\
\hline Male & 1.1 & $0.9-1.3$ & 1.0 & $0.8-1.2$ \\
\hline \multicolumn{5}{|l|}{ Residence } \\
\hline Urban & 1.00 & & 1.0 & \\
\hline Rural & 1.2 & $0.9-1.5$ & 1.1 & $0.9-1.4$ \\
\hline \multicolumn{5}{|l|}{ Literacy } \\
\hline Literate & 1.0 & & 1.00 & \\
\hline Illiterate & 2.4 & $1.9-3.2$ & 1.5 & $1.2-2.0$ \\
\hline \multicolumn{5}{|l|}{ Marital status } \\
\hline Married & 1.00 & & 1.0 & \\
\hline Unmarried & 2.5 & $2.0-3.0$ & 1.3 & $1.0-1.6$ \\
\hline \multicolumn{5}{|l|}{ Geopolitical zone } \\
\hline South West & 1.00 & & 1.00 & \\
\hline North West & 1.2 & $0.8-1.7$ & 1.5 & $1.1-2.1$ \\
\hline South-South & 1.3 & $0.9-1.9$ & 1.5 & $1.1-2.1$ \\
\hline North Central & 1.4 & $1.0-2.0$ & 1.5 & $1.1-2.2$ \\
\hline North East & 1.5 & $1.0-2.2$ & 2.0 & $1.3-2.9$ \\
\hline South East & 1.6 & $1.2-2.1$ & 1.5 & $1.1-2.0$ \\
\hline
\end{tabular}


TABle 4. Relationship of Age, Geopolitical Zone, Sex, and Marital Status with Functional Low Vision for Literate and Illiterate Persons*

\begin{tabular}{|c|c|c|c|c|c|c|}
\hline \multirow[b]{2}{*}{ Parameter } & \multicolumn{2}{|c|}{ Literate } & \multicolumn{2}{|c|}{ Illiterate } & \multirow[b]{2}{*}{$95 \%$ CI } & \multirow[b]{2}{*}{$\boldsymbol{P}$} \\
\hline & OR & $95 \%$ CI & $\boldsymbol{P}$ & OR & & \\
\hline \multicolumn{7}{|l|}{ Age group, y } \\
\hline $40-49$ & 1.00 & & & 1.0 & & \\
\hline $50-59$ & 1.3 & $0.8-2.2$ & 0.341 & 1.6 & $0.9-2.7$ & 0.098 \\
\hline $60-69$ & 2.5 & $1.4-4.5$ & 0.003 & 5.5 & $3.3-9.3$ & 0.001 \\
\hline $70-09$ & 8.5 & $4.9-15.0$ & 0.001 & 5.9 & $3.3-10.5$ & 0.001 \\
\hline $80+$ & 15.4 & $7.4-32.3$ & 0.001 & 10.8 & $5.9-19.8$ & 0.001 \\
\hline \multicolumn{7}{|l|}{ Geopolitical zone } \\
\hline South West & 1.0 & & & 1.00 & & \\
\hline North Central & 1.0 & $0.4-2.5$ & 1.000 & 1.4 & $0.9-2.2$ & 0.097 \\
\hline North East & 1.6 & $0.9-3.0$ & 0.134 & 1.6 & $0.9-3.0$ & 0.128 \\
\hline North West & 1.3 & $0.6-2.9$ & 0.463 & 1.6 & $1.1-2.4$ & 0.014 \\
\hline South East & 1.6 & $0.7-3.3$ & 0.249 & 1.3 & $0.9-1.9$ & 0.160 \\
\hline South-South & 1.3 & $0.7-2.3$ & 0.345 & 1.4 & $0.9-2.2$ & 0.145 \\
\hline \multicolumn{7}{|l|}{ Sex } \\
\hline Female & 1.0 & & & 1.0 & & \\
\hline Male & 1.7 & $0.9-3.4$ & 0.096 & 1.3 & $1.0-1.8$ & 0.075 \\
\hline \multicolumn{7}{|l|}{ Marital status } \\
\hline Currently married & 1.0 & & & 1.0 & & \\
\hline Currently unmarried & 25.4 & $1.4-4.1$ & 0.001 & 1.3 & $0.9-1.8$ & 0.098 \\
\hline
\end{tabular}

${ }^{*}$ Data are given as adjusted odds ratios (95\% confidence intervals), obtained by multiple logistic regression. Separate models were fitted for literate and illiterate.

being more likely to have visual loss from corneal diseases such as trachoma.

The variation in prevalence of FLV by GPZ reflects the same pattern as the distribution of blindness from all causes, which was highest in the northern parts of the country. There are two probable explanations for this variation: first, northern areas are poorer and drier than the south, and trachoma is more common in the northern savanna/sahel regions of the country. Second, although the whole country is underserved in terms of eye care services, the northern areas are particularly underserved, with many of the states having only one or two ophthalmologists per million population. This means that conditions such as corneal ulceration, trachomatous trichiasis, and glaucoma, which could have been treated to prevent visual loss, are not being detected early or adequately managed.

The strengths of this survey are its size, the sophistication of the methods used, and the skills and continuity of the clinicians performing the assessments and diagnostic examinations.

In Nigeria there is a large unmet need for low vision services because these are currently being provided by only a very

TABLE 5. Estimated Prevalence of Functional Low Vision and Total Blindness and Estimates of the Number Affected in Nigeria as a Whole and per Million Total Population

\begin{tabular}{ccccc}
\hline & & & \multicolumn{2}{c}{$\begin{array}{c}\text { Estimate of Number } \\
\text { Affected }\end{array}$} \\
\cline { 3 - 5 } & & & & $\begin{array}{c}\text { Minimum per } \\
\text { Million } \\
\text { Population }\end{array}$ \\
\hline $\begin{array}{c}\text { Functional low } \\
\text { vision }\end{array}$ & 2.7 & $2.3-3.1$ & 755,230 & 4,962 \\
$\begin{array}{c}\text { Bilateral no light } \\
\text { perception }\end{array}$ & 0.2 & $0.1-0.3$ & 52,199 & 343 \\
\hline
\end{tabular}

US Census IDB estimates of Nigeria population by age and sex for 2010 were used in the calculation. It was assumed that there were no individuals younger than 40 years in the estimation of minimum per million total population. limited number of eye units. The provision of low vision services requires the input of experienced optometrists, as well as ophthalmologists and rehabilitation workers. A study in India suggested that providers of services may themselves be important barriers to a low vision service because they lack training, skills, and knowledge of low vision. ${ }^{22}$ Even in the United Kingdom, low vision service provision is inadequate and there are geographical variations, with some regions being poorly served compared with others. ${ }^{23}$ The challenge for Nigeria is enormous, but it has been shown that there is much that can be done with minimal training, equipment, and resources, particularly in the area of nonoptical interventions such as using color coding and increasing contrast. Indeed, in Nigeria, given the relatively low level of literacy among those with FLV, the emphasis of low vision services may need to be on environmental modification and nonoptical interventions, which promote mobility and independence, rather than on optical interventions (e.g., magnifiers). The SmartSight model of low vision rehabilitation advocated by the American Academy of Ophthalmology ${ }^{24}$ could, with modification to the situation in Nigeria, provide a useful point from which to expand the provision of services for people with incurable visual loss.

\section{Acknowledgments}

The authors thank Oye Quaye for managing the finances for the study; Auwal Shehu and Dania Charles for data entry; and the teams of ophthalmic nurses, enumerators, interviewers, liaison officers, drivers, and cooks in the six geopolitical zones who assisted in data collection. The Federal Ministry of Health, State governments and Local governments provided accommodation to the survey teams and other administrative and logistic support during the survey.

\section{References}

1. Lamoureux EL, Pallant JF, Pesudovs K, Rees G, Hassell JB, Keeffe JE. The effectiveness of low-vision rehabilitation on participation in daily living and quality of life. Invest Opbthalmol Vis Sci. 2007; $48: 1476-1482$.

2. Reeves BC, Harper RA, Russell WB. Health Services Research Unit, London School of Hygiene, UK. Enhanced low vision rehabilitation 
for people with age related macular degeneration: a randomised controlled trial. Br J Ophthalmol. 2004;88:1443-1449.

3. Stelmack JA, Tang XC, Reda DJ, Rinne S, Mancil RM, Massof RW; LOVIT Study Group. Outcomes of the Veterans Affairs Low Vision Intervention Trial (LOVIT). Arch Ophthalmol. 2008;126:608-617.

4. World Health Organization (WHO). The management of low vision in children. Report of a WHO Consultation, Bangkok, July 1992. Geneva: WHO; 1993.

5. Shah SP, Minto H, Jadoon MZ, et al. Prevalence and causes of functional low vision and implications for services: the Pakistan National Blindness and Visual Impairment Survey. Invest Ophthalmol Vis Sci. 2008;49:887-893.

6. Gilbert CE, Ellwein LB. The prevalence and causes of functional low vision in school-age children: results from standardized population surveys conducted in Asia, Africa, and Latin America. Invest Ophthalmol Vis Sci. 2008;49:877-881.

7. Christy B, Keeffe JE, Nirmalan PK, Rao GN. A randomised controlled trial assessing the effectiveness of strategies delivering low vision rehabilitation: design and baseline characteristics of study population. Ophthalmic Epidemiol. 2010;17:203-216.

8. O'Connor PM, Lamoureux EL, Keeffe JE. Predicting the need for low vision rehabilitation services. Br J Ophthalmol. 2008;92:252255.

9. World Health Organization (WHO). Global Initiative for the Elimination of Avoidable Blindness. WHO/PBL/97.61. Geneva: WHO; 1997.

10. Dandona L, Dandona R, Srinivas M, et al. Blindness in the Indian state of Andhra Pradesh. Invest Ophthalmol Vis Sci. 2001;42:908 916.

11. Chiang PC, O'Connor PM, Keeffe JE. Low vision service provision a global perspective. Expert Rev Ophthalmol. 2007;2:661-874.

12. Dineen B, Gilbert C, Rabiu MM, et al. The Nigerian National Blindness and Visual Impairment Survey: rationale, objectives and detailed methodology. BMC Ophthalmol. 2008;8:Art. 17.

13. Kyari F, Murthy GVS, Sivsubramaniam S, et al. Prevalence of blindness and visual impairment in Nigeria: the National Blindness and Visual Impairment Survey. Invest Ophthalmol Vis Sci. 2009;50: 2033-2039.

14. Abdull MM, Sivasubramaniam S, Murthy GVS, et al. Causes of blindness and visual impairment in Nigeria: the Nigeria National Blindness and Visual Impairment Survey. Invest Ophthalmol Vis Sci. 2009;50:114-120.
15. Imam AU, Gilbert CE, Sivasubramaniam S, Murthy GVS, Maini R, Rabiu MM. Outcome of cataract surgery in Nigeria: visual acuity, autorefraction and optimal intraocular lens powers. Results from Nigeria National Survey. Ophthalmology. 2011;118:719-724.

16. Rosser DA, Laidlaw DA, Murdoch IE. The development of a "reduced logMAR" visual acuity chart for use in routine clinical practice. BrJ Ophthalmol. 2001;85:432-436.

17. Bourne R, Dineen B, Jadoon Z, et al. The Pakistan national blindness and visual impairment survey: research design, eye examination methodology and results of the pilot study. Ophthalmic Epidemiol. 2005;12:321-333.

18. Bourne RR, Dineen B, Modasser AS, Mohammed NHD, Johnson GJ. The National Blindness and Low Vision Prevalence Survey of Bangladesh: research design, eye examination methodology and results of the pilot study. Ophthalmic Epidemiol. 2002;9:119-132.

19. World Health Organization (WHO). Coding Instructions for the WHO/PBL Eye Examination Record (version III). PBL/88.1. Geneva: WHO; 1988.

20. World Health Organization (WHO), Geneva. Consultation on Development of Standards for Characterization of Visual Loss and Visual Functioning. WHO/PBL/03.91. Geneva, WHO; 2003.

21. US Census Bureau International Data Base. http://www.census gov/ipc/www/idb/nigeria.php. Accessed December 30, 2010.

22. Khan SA, Shamanna BR, Nuthethi R. Perceived barriers to the provision of low vision services among ophthalmologists in India. Indian J Ophthalmol. 2005;53:69-75.

23. Culham LE, Ryan B, Jackson AJ, et al. Low vision services for vision rehabilitation in the United Kingdom. Br J Ophthalmol. 2002;86: 743-747.

24. Jackson ML. Vision rehabilitation for Canadians with less than 20/40 acuity: the SmartSight model. Can J Ophthalmol. 2006;41: 355-361.

\section{APPENDix}

\section{Nigeria National Blindness and Visual Impairment Study Group}

In addition to the authors of this article, the study group includes Adenike Abiose, Bankole Olufunmilayo, Fatima Kyari, Hannah Faal, A. U. Imam, Mohammed M. Abdull, Pak Sang Lee, and Tafida Abubakar. 